\title{
Mechanical Contributions to Muscle Injury: Implications for Athletic Injury Risk Mitigation
}

\author{
Judd T. Kalkhoven ${ }^{1} \&$ Mark L. Watsford ${ }^{1}$ \\ ${ }^{1}$ Faculty of Health, University of Technology Sydney
}

April 9, 2020

\begin{abstract}
Muscular injury continues to be a significant burden on athletes. Through developing proper understandings of the mechanical contributions to muscle injury, appropriate intervention protocols can be established to reduce injury risk. The strength, stiffness, length, and elastic properties of the musculotendinous unit underpin the resilience of the structure. The capacity of individual muscles and tendons to absorb elastic energy, protect against high forces, resist length changes and tolerate strain encapsulate the capacity of the musculotendinous unit to avoid injury. Further, the contributions of intersarcomere dynamics to muscle injury are of utmost importance. Considering that muscle injury appears to be more strongly related to muscle fiber strain, opposed to stress, athletes should seek strategies that provide them with the capacity to resist excess strain, which is achieved through correct muscle activation timing, heightened strength and superior stiffness regulation capabilities. Further, athletes should strive to increase their capacity to withstand larger amounts of absolute strain, which can be achieved through increasing the length and maximal elongation capabilities of the structures subject to length changes, such as fascicles.
\end{abstract}

Keywords: Musculotendinous unit; Strain; Strength; Stiffness; Sarcomere; Fascicle length

DOI: http://dx.doi.org/10.31236/osf.io/a5um4

Citation: Kalkhoven, J. T. \& Watsford, M. L., (2020). Mechanical Contributions to Muscle Injury; Implications for Athletic Injury Risk Mitigation. SportRxiv. Doi:10.31236/osf.io/a5um4

Corresponding author: Judd Kalkhoven (Judd.kalkhoven@uts.edu.au) This work is a preprint and has yet to be peer-reviewed.

All authors have read and approved this version of the manuscript for pre-print.

Twitter handles: @KalkhovenJudd 


\section{TABLE OF CONTENTS}

1. Introduction

2. Relationship between stress, strain, and muscle injury

2.1 Muscle strain injury

2.2 Role of active and passive components of the musculotendinous unit in strain management

2.3 Intersarcomere dynamics

3. Considerations for athletic injury risk mitigation

4. Methods to alter muscular stiffness, strength, and strain tolerance

5. Conclusions

6. Practical Applications

\section{Key Points}

1. Considerable advances in the field of muscle mechanics have been achieved in the past two decades. Despite this progress, translation of this research into applied sports settings in the context of injury is limited.

2. The contributions of stress, strain, muscle activation timing, and intersarcomere dynamics are fundamental to muscle injury occurrence.

3. Based on the available literature, more extensive injury risk mitigation protocols centred on stiffness, strength and strain tolerance should be established.

\subsection{INTRODUCTION}

Muscular injuries are consistently the most prevalent time-loss injury across a multitude of sports including but not limited to soccer [1, 2], Australian football (AFL) [3-6], and tennis [7]. Considerably high muscular injury rates have also been reported in other sports [8-18]. Through developing proper understandings of the mechanisms contributing to muscle injury, appropriate intervention protocols can be established to increase muscular resilience and decrease the likelihood of acute muscle injury events. The strength, stiffness, length, and elastic properties of the musculotendinous unit (MTU) underpin the resilience of the relevant structures. Specifically, the capacity of individual muscles and tendons to absorb elastic energy, protect against high forces, resist length changes and tolerate strain encapsulate the capabilities of the MTU to resist injury.

The resilience of a muscle to injury and damage is largely dependent on its capacity to manage stress (applied load per cross sectional area), strain (length change), and more specifically, strain under stressful conditions [19-22]. To date, it appears that although stress and strain are inter-related, muscle damage is largely dependent on the strain experienced by the muscle rather than the stress imposed during muscle contraction [19-22]. Specifically, there is strong evidence to suggest that muscle injury typically occurs when the muscle is subjected to strain during high levels of muscle activation and heightened tension [1922]. When muscular stress increases, tetanic tension largely remains unchanged [20], demonstrating that muscular integrity, structural stiffness, and Young's modulus are largely maintained under high stresses. This also reflects that muscle can still work optimally and maintain large force outputs under highly stressful conditions. However, when subjected to strain muscular tension decreases [19-22], inevitably reducing stiffness and Young's modulus. This results in heightened exposure of the musculature to strain for a given applied force and reduces muscle force production, reflecting muscular impairment. Within the context of this paper, stiffness is defined as the extent to which an object resists deformation in response to an applied force while Young's modulus is defined as the ratio of stress to strain.

\subsection{RELATIONSHIP BETWEEN STRESS, STRAIN AND MUSCLE INJURY}

Exposure to physical stress and strain is an essential component of competing in sport and is largely unavoidable for almost all athletic pursuits. Some athletes, such as most power athletes, experience considerably large acute forces and physical stresses, exposing these athletes to a substantially greater risk of acute strain injury. There is much debate regarding the appropriate intervention strategies that best protect against muscular injury. Proper understandings of the mechanics of the MTU and the mechanisms that govern muscle injury are of utmost importance for facilitating the formation of strategies that best prevent mechanical failure (injury) of the tissue in question. This section specifically explores the mechanisms that contribute to muscle strain injuries.

\subsection{Muscle strain injury}

There is considerable ambiguity regarding definitions of muscle damage and injury. Recently, calls to clearly differentiate between muscle damage and injury have surfaced [23] with muscle strain injury defined as a rupture of individual muscle fibers that can extend 
across a portion of fibers within a particular muscle (partial tear) or across the whole muscle (complete tear) $[23,24]$. By contrast, muscle damage has been defined as a disruption to myofibrils within a muscle fiber, whereby the architecture of the sarcomeres becomes disorganized [23, 25]. A causal link between the two entities whereby microscopic damage precedes macroscopic injury has been suggested [26, 27], however, it is important to acknowledge that some authors do not distinguish between muscle damage and muscle strain injury and have described them as the same clinical entity [28, 29]. These conflicting approaches yield considerable challenges for interpreting existing research. Regardless of whether muscle damage and injury are part of the same entity or not, many common characteristics are shared. Considering the absence of a consensus surrounding the differences between muscle damage and muscle injury, they will largely be explored in tandem within the following text.

Considering that muscular injury and damage typically present when the muscle is strained during high muscle tensions, speculation that high tensions cause muscular injury is expected. However, the clinical research observing muscular injury does not support this doctrine $[19,20]$. When assessing the stress/strain relationships of muscles, muscular damage appears to be more strongly related to the fiber strain (stretch/length change) magnitude rather than the absolute stress (force/pressure) imposed on the fiber $[19,20,25]$. However, the two are not mutually exclusive as more specifically, it appears that muscle injury and damage occurs when exposed to strain under conditions of high muscle tension [19-22, 30]. Lieber \& Friden [20] demonstrated that in rabbit tibialis anterior muscles stimulated to maximal tetanic tensions but with differing maximal tensions due to stimulation timing (40\% greater in the late stretch group), tetanic tension decreased by approximately the same magnitude in all muscles assessed when receiving the same deformation pattern (25\% strain). The follow up tetanic tensions signified that both groups likely sustained similar amounts of muscle damage and muscular function impairments despite varying stress exposures, indicating that muscle damage induced by eccentric contractions was not directly related to the stress imposed upon it. Interestingly, in a similar experiment assessing the contractile and morphological properties of the tibialis anterior of rabbits in response to passive stretching, isometric contractions, and eccentric contractions, maximal tetanic tensions were reduced by $13 \%, 31 \%$, and $69 \%$ respectively 1-hour post-treatment [30]. In this experiment both the isometric and eccentric contraction conditions involved maximal tetanic contractions through supramaximal stimulation of the nerve and complete muscle activation. The greater muscular damage exhibited in the eccentric contraction group, relative to the isometric contraction group, conceivably resulted from the strain experienced rather than the absolute stress imposed on the muscle. Further, the muscle damage presented in the eccentric group relative to the passive stretch group suggested that considerably greater muscular damage specifically occurred when strain was experienced under high muscle tensions. Similar experiments have produced results that largely support the findings above [19, 21].

These results mirror standard spring and material deformation principles whereby increases in structural stiffness, which in the case of muscle results from heightened muscle tensions [31,32], elevate the energy storage capacity of the muscle for a given strain and aid muscular strain resistance for a given applied load [19]. Suggestions that muscle activation timing may contribute substantially to muscle injury are warranted as greater levels of muscular activation are generally favorable for resisting strain due to greater stiffness and a heightened Young's modulus. In support, the force at which lengthening and subsequent injury occurs is significantly greater during muscular contraction than during passive muscular stretch [19]. Further, Butterfield \& Herzog [33] showed that muscle activation timing greatly influenced muscle fiber strain magnitude, while eccentrically contracting muscles undergoing high levels of muscle activation absorbed considerably more mechanical energy than muscles with low level activation prior to muscle injury [19]. Accordingly, the correct muscle activation timing and maintenance of muscle tension under large external and internal stress, reflecting preserved muscular functioning and crossbridge formation, is important for reducing injury risk in many scenarios. However, similar to standard spring and material systems, the heightened tension-induced stiffness reduces the capacity of the structure to tolerate absolute strain. It follows that when comparing highly stiff and compliant mechanical structures, stiff structures typically display a reduced capacity to manage absolute length changes. This is reflected in the stiffer, active musculature as it is at an elevated risk of experiencing more severe injury and muscle damage compared to the more compliant, passive musculature when subjected to rapid length changes. This mechanical relationship explains, in part, why passive musculature has shown a superior capability to manage greater length changes than active musculature without being subjected to damage [19-21].

Of further importance to muscular injury understandings are the effect of strain rate on injury severity, absolute strain tolerance, and injury location. Brooks \& Faulkner [34] demonstrated that greater 
muscular elongation velocities increase the severity of muscular strain injury in the extensor digitorum longus muscles of mice, but only during large muscular strains. Importantly, during lesser strains the effect of strain rate on muscular injury was not significant, leading to conclusions that velocity may play a minor role in contraction-induced injury but its importance is negligible relative to that of strain. These findings were supportive of previous studies whereby strain velocity does not appear to influence muscular damage during smaller muscular strains [22, 35, 36]. Interestingly, during larger strains (30\%), Warren et al. [37] also reported that a small percentage of variation in the force deficit was explained by velocity, however, this was at a relatively low strain velocity (25\% maximal velocity). Despite this preliminary research, further examination of the effect of high strain rates during larger muscular strains is needed to deepen the understanding of the influence of strain rate on muscular damage and injury.

When considering injury location, Garrett et al. [38] and Best et al. [39] both investigated the effect of strain rate on muscle injury site. At strain rates of 1,10 , and $100 \mathrm{~cm} / \mathrm{min}$, the vast majority of strain injuries in the tibialis anterior, extensor digitorum longus, and rectus femoris muscles of rabbits occurred at the distal musculotendinous junction $(98.6 \%)$ while elongation speed had no effect on injury location [38]. In the gastrocnemius, injury still occurred at musculotendinous junctions but also at various junctions across the complex architecture of this muscle, however, elongation speed had no effect on injury location. Interestingly, at higher strain rates $(100 \mathrm{~cm} / \mathrm{s})$ muscle injury occurred at the distal muscle belly [39] while at slower strain rates $(4 \mathrm{~cm} / \mathrm{s}$ and $40 \mathrm{~cm} / \mathrm{s}$ ) injury occurred at the distal musculotendinous junction, mimicking the findings of Garrett et al. [38]. It appears that the effect of strain rate on the damage sustained by muscle is not well understood and further research is required to improve the understanding of the role of strain rate in muscle injury occurrence.

\subsection{Role of active and passive components of the musculotendinous unit in strain management}

To enable the establishment of intervention protocols that protect against severe muscle injury, a thorough understanding of sarcomere mechanics as they relate to muscle injury and damage is required. Some understanding of the damage that occurs within the contractile and cytoskeletal components of muscle fibers during eccentric-induced injury are of interest for determining the type of damage experienced within the muscle. According to Friden et al. [25], injuries to muscle fiber contractile and cytoskeletal components following eccentric exercise typically include Z-band streaming and dissolution [40-46], A-band disruption
[43, 47, 48], disintegration of the intermediate filament system and the loss of intracellular desmin [46, 49], and misalignment of the myofibrils [40-46]. Further, structural abnormalities following various types of exercise include primary or secondary sarcolemma disruption [50-52], swelling or disruption of the sarcotubular system [50], distortion of the myofibril contractile components [40-44, 47, 53, 54], cytoskeletal damage [49], and extracellular myofiber matrix abnormalities [55]. Of particular interest within the context of this paper are the structures that manage strain within the muscle fiber such as, titin, nebulin, desmin and the M-band as these influence and assist the maintenance of sarcomere and muscle fiber integrity [56-59]. However, it is worth noting that the loss of some filaments during eccentric loading, such as desmin, may also be attributed to enzymatic hydrolysis resulting from an influx of calcium due to muscle fiber strain as opposed to mechanical overload only [60].

In an attempt to explain muscle damage Morgan [61] describes a phenomenon whereby sarcomeres 'pop' when lengthened outside the range of crossbridge formation. During the 'popped' condition the passive structures of the sarcomere primarily support the tension. This 'popping' indicates the importance of the passive sarcomere structures to strain management as these structures hold a significant role in axial continuity of the myofilaments for the production of resting tension, stretch resistance and maintenance of Z-disk integrity [59, 62]. Further, it has been shown that damage to passive elements did not occur until passive fiber segments were stretched beyond thick and thin filament overlap [63]. Although fiber damage occurs during these conditions, the 'popping' of sarcomeres [61] may be a protective mechanism for active muscles exposed to rapid length changes as this 'popping' occurs in the weakest sarcomeres that are scattered throughout the length of the muscle fiber, and consequently reduce the stiffness and tension of the muscle fiber for a given fiber length. This reduction in muscular tension and stiffness would be expected to better accommodate length changes, potentially protecting the muscle from more substantial damage and injury.

In contrast to active musculature, passive stretch of the muscles does not typically produce ultrastructural damage or contractile changes [20]. Since muscle tension is minimal under passive conditions, the accompanying stiffness reduction appears to allow for greater length changes within the musculature. More specifically, in passive musculature, there are reduced linkages formed between crossbridges, reducing total muscle stiffness [61, 64-68]. It appears that under passive conditions strain is managed within the passive 
components of the MTU such as tendons, connective tissue, and the non-active components of musculature [56-59]. The specific roles of the passive muscular filaments are currently a highly active area of investigation as researchers attempt to explain a number of occurrences that are currently unaccounted for in Huxley's crossbridge theory [69]. Of particular interest is the role of titin which has been identified as contributing substantially to muscle stiffness regulation. It has been suggested that titin behaves as an adaptable spring that increases engagement during muscle activation as a winding filament [70-72] with its stiffness being further modulated by the binding of calcium to the titin filament [73, 74], providing a possible contribution to the residual force enhancement phenomenon [70]. Further insight into the specific roles of the various passive filaments and proteins is outside the scope of this review, however, their inclusion within this paper is warranted to highlight their importance to maintaining muscle structure and functioning as well as the modulation of passive and active muscle stiffness.

It is important to note that cytoskeletal components of muscles are rarely damaged under passive conditions since healthy musculature, when inactive, appears to handle length changes beyond the working range of motion of the joints without being subject to injury [75]. As a result, it appears that injury occurs in other structures, such as joints, when the musculature is inactive or highly compliant [75-78]. Overall, it appears that muscle activation plays a significant role in mitigating the risk of injuries to the joint, bone, and cartilage. Further, injury to musculature may be relatively favorable considering the expedited recovery rates of musculature in comparison to joint, tendon and/or other connective tissue [79, 80]. Since individuals have the ability to alter the stiffness properties of their limbs through the activation of musculature and stretch reflex activity, it appears that humans and mammals actively adjust their stiffness properties through altering muscle activation in anticipation of, or response to large stresses or length changes within the musculature [81-85] which may have implications for fiber dynamics [33].

\subsection{Intersarcomere dynamics}

A more detailed exploration of the intersarcomere dynamics within single muscle fibers may provide important insights into the underlying mechanisms of muscle injury occurrence. The sarcomeres of single muscle fibers, and more specifically myofibrils, vary in both length [86, 87] and shortening velocity [68]. In frog muscle fibers, the sarcomeres closer to the ends of the fiber are typically shorter in length and shorten at heightened velocities relative to the sarcomeres closer to the centre [87]. These length discrepancies appear to become further exaggerated during muscle activation [87]. Sarcomere-length non-uniformity [61, 88, 89], which proposes the non-uniform lengthening of sarcomeres across a muscle fiber during a number of various muscular conditions under stretch, is now widely accepted [61, 88, 89]. Considering differences in sarcomere lengthening characteristics exist, individual sarcomeres display varying yield point profiles. These discrepancies in sarcomere dynamics may also result in mismatches between sarcomeres in terms of the forces they sustain [25]. Variations in sarcomere loading and structural load tolerances may explain a number of occurrences regarding muscular injury. For example, these differences likely account for why certain sarcomeres are 'popped' beyond actinmyosin filament overlap before others, as well as why certain sarcomeres within a single fiber are at a greater risk of structural failure. Further, such events led the separation of non-uniformly lengthened sarcomeres into two distinct groups, with one set of sarcomeres at a specific point on the descending limb of the force length profile relying primarily on active force, and the other set at a specific length beyond actin-myosin filament overlap (popped sarcomeres) relying exclusively on passive force [89].

During isometric and concentric contractions, tissue stretching is typically considered to be minimal, limiting muscle damage and injury risk. Muscular damage and injury appear to be more common during eccentric contractions when compared to other forms of contraction [19-21]. Within the muscle fiber, variations in the mechanical characteristics of sarcomeres appear to result in weaker sarcomeres lengthening, and therefore experiencing strain during these types of contractions [61, 87, 90]. Interestingly, within a single muscle fiber some sarcomeres, or groups of sarcomeres, may behave isometrically or even concentrically whilst other, less stiff and actively weaker sarcomeres are lengthened outside their active range. In support of such a phenomenon Burton et al [90] and Lieber \& Baskin [87] demonstrated that in frog muscle fibers the shorter sarcomeres at the extreme ends of the fiber commonly shorten while the central sarcomeres lengthen during fixed end tetani. Of further importance is the presence of a transition zone of sarcomeres which includes sarcomeres of intermediate lengths [87, 91]. These differences in sarcomere behaviour may provide a more thorough explanation of muscular injury occurrence, potentially even explaining why muscular injury has been reported, although rarely, during isometric and concentric contractions [92, 93]. In such a scenario, the strain experienced by the lengthening sarcomeres exposes them to damage [94] and a risk of mechanical failure. Further, such findings suggest that the transition phase between muscle contraction types may 
be an area of interest that warrants further research in relation to intersarcomere behavior, distribution of load within muscles, and injury occurrence.

Interestingly, the primary site of muscle injury and damage in humans is much debated with some researchers suggesting that the majority of muscles appear to be most commonly injured near the musculotendinous junction at the both the proximal and distal regions [19, 24, 95] while others maintain that the mid-belly of a muscle is most at risk [96-100]. Considering the more central sarcomeres are more likely subjected to lengthening it is expected that these would be the sarcomeres at a greater risk of mechanical failure. However, several investigators have shown that the extensibility of terminal sarcomeres is reduced relative to sarcomeres throughout the rest of the muscle $[86,101]$ and when considering that the ends of muscles typically display a reduced cross-sectional area compared to the mid-belly, it is possible that the end regions may be most likely to experience severe injury. Muscular injury may alternatively be explained by Morgan's proposal that although the shortest sarcomeres are concentrated at the ends of a fiber, the structurally weakest sarcomeres may be scattered throughout most of the length [61]. Importantly, the majority of research in this area has not been conducted with human muscle tissue, instead focusing on animal tissue, emphasizing the need for additional investigation. The nature of intersarcomere relationships is complex and although a comprehensive exploration of this topic is outside the scope of this review, acknowledgement of the importance of these mechanical characteristics to injury occurrence is strongly emphasized. Further research into intersarcomere dynamics is clearly required to enhance the understanding of the topic as this may have considerable implications for muscular injury in athletes and the development of appropriate injury risk mitigation protocols.

\subsection{CONSIDERATIONS FOR ATHLETIC INJURY RISK MITIGATION}

It is well known that muscular injury risk is greater during high intensity athletic activities compared with low intensity activities, especially when high intensity eccentric loading is experienced [19, 20, 95, 102]. In elite sprinters, Yeung et al. [103] reported an injury rate of 0.87 per 1000 hours of exposure. In team sports where sprinting and kicking are common, muscular injury continues to be a major burden for athletes. Within the Australian Football League (AFL), muscular injury is the most prevalent type of injury resulting in loss of game time [3-6] with hamstring, groin, quadriceps and calf strains accounting for four of the top five most common injuries [6]. Further, it has been demonstrated that the likelihood of muscular injury increases when AFL players perform greater amounts of high-speed running than that to which they were accustomed [104]. Parallel findings have been reported in men's professional soccer with muscular injury contributing 20-37\% of all time-loss injuries [1]. Similar to the AFL, the four most common muscular injuries reported in soccer are strains to the hamstring (37\%), adductor (23\%), quadriceps (19\%), and calf (13\%) [1] with hamstring strains the most common in positions that require the greatest amount of sprinting [2, 105-109]. Other research across team sports such as rugby union [12] and NFL [2, 13, 14] as well as individual sports such as tennis [7], water skiing [15, 16], dancing [17], bull riding [15], and judo [18] further highlight the prevalence of muscular injury across the sporting arena. Considering the elevated muscle tensions, forces, strains and contraction velocities experienced during high intensity activities such as sprinting, it is evident that these activities subject the musculature to greater acute loading.

Although a multitude of research has indicated that exposure to high intensity activity increases the risk of muscular injury [104, 110], careful strategy formation to reduce injury risk in response to these findings is needed as reductions in high intensity exposure may have considerable costs to performance outcomes and may even increase injury risk when an athlete is required to partake in high intensity activities [111]. Indeed, both Duhig et al. [104] and Gabbett et al. [110] maintain that cautious training and activity load management is desired to achieve optimal athletic performance whilst ensuring athletes avoid injury. It is also important to emphasize the role of overload and high intensity activity exposure for inducing favourable adaptations that enhance athletic performance [112-116]. As such, athletes should seek strategies that encourage favourable physiological and mechanical adaptations that develop athlete resilience and best accustom athletic bodies to the heightened stresses and strains experienced during elite performance outputs.

There are a number of beneficial strategies that have reduced muscular injury risk through the development of muscular resilience and many of these may also enhance performance outcomes. Considering the primary mechanism of injury is muscular strain, athletes should seek to 1) implement strategies that increase their capacity to resist excessive muscle strain, which can be achieved through improved strength development and active stiffness regulation as well as correct muscle activation timing and 2) seek to increase the MTU's capacity to withstand larger amounts of absolute strain, which can be achieved through 
increasing the length and maximal elongations of the structures subjected to length changes, such as fascicles. Interestingly, unlike common understandings of immutable, non-biological materials or spring systems where an increase in length results in a reduction in stiffness, biological matter does not necessarily share these same characteristics as they can adapt to specific stimuli [117-122]. Simultaneous increases in stiffness and length characteristics have been well documented in biological structures with one such example being the maturity of mammals from infants through to adulthood whereby tendinous and muscular structures simultaneously increase in stiffness and length during growth into adulthood [123126]. Interestingly, it appears that exercise may also induce similar adaptations in response to various forms of training [119-121, 123, 127-141].

Considering strain is the primary mechanism by which muscular injury occurs, athletes should seek methods to resist excessive muscular strain. However, it is important to note that muscular strain and eccentric contractions are fundamental components of human locomotion and the utilisation of the stretch shorten cycle. For example, a number of researchers have determined that the hamstrings behave eccentrically during the late swing phase of sprinting [142-144] along with the stance phase [144], however, the latter is less certain. Further, eccentric muscle actions are an essential component of the counter movement jump [145]. As such, eccentric loading, for the most part, is a fundamental component of movement across a number of athletic activities and is largely unavoidable. With this in mind, athletes should seek to develop their capacity to more effectively regulate the amount of strain experienced in any given scenario and reduce the likelihood of experiencing excess strain, particularly under high loads. This can be achieved through the development of an individual's capabilities to modulate and elevate muscular tensions and stiffness. It is worth emphasizing that active muscle strength and active muscle stiffness are closely related and unlike most mechanical structures, the stiffness properties of musculature can be readily altered through an increase or decrease in muscle activation and active muscle tensions $[83,84]$. The capability of an individual to readily adjust the mechanical properties of the body is highly advantageous as when muscle stretch is required, such as during passive stretching, individuals can actively reduce tension to accommodate muscle lengthening. However, in scenarios where large loads are applied and strain requires resistance, such as during heavy weight lifting or certain phases of sprinting, precise muscle activation timing, and greater amounts of muscular strength and stiffness are important.

\subsection{METHODS TO ALTER MUSCULAR STIFFNESS, STRENGTH AND STRAIN TOLERANCE}

Considering the benefits to muscle resilience and the multitude of reports linking stiffness, strength, and performance outputs [121, 145-158], it is of interest to explore methods to modify stiffness and strength properties of the body. Various forms of strength training have resulted in heightened stiffness and strength, including eccentric strength training [159, 160], isometric strength training [148, 161], and general weight training [121]. Increases in various lower body stiffness measures, including musculotendinous stiffness, leg stiffness, and tendon stiffness, along with strength have also resulted from plyometric training protocols [121, 148, 162]. These findings are in line with a multitude of studies exhibiting reductions in injury risk and improved athletic performance with these types of training and provide a mechanical explanation for why these training methods have a positive influence on injury risk mitigation and athletic performance outcomes.

In contrast, flexibility training has been reported to reduce stiffness both acutely [163] and chronically [164]. Increased range of motion (ROM) achieved with acute bouts of stretching has been attributed to changes in the length and stiffness of the affected limb MTU $[165,166]$. Although the exact mechanisms responsible for chronic or plastic increases in ROM are debatable, the improvements have been primarily attributed to reductions in MTU stiffness [164, 167] as well as an increased tolerance to stretch [168] potentially due to a greater number of sarcomeres in series [169]. However, a number of researchers have concluded that stretching has no effect on injury risk mitigation [170-172] while others have illustrated that the most flexible individuals were more likely to suffer injuries than moderately flexible individuals [173, 174]. Furthermore, a substantial body of research appeared early in this century revealing that sustained static stretching could impair subsequent performance [175-182]. Considering these findings and the reductions in stiffness associated with static stretching, it appears that athletes should avoid static stretching unless their sporting pursuits require ROM's far beyond those typically experienced in every day athletic pursuits, such as with ballerinas. The reductions in stiffness and strength, along with the multitude of performance impairments associated with static stretching appear disadvantageous to athletes. However, dynamic and proprioceptive neuromuscular facilitation (PNF) stretching may still be of benefit to athletes, confirmed by research reporting performance improvements with these types of stretches [183-191]. 
A cautious approach when implementing these stretches is emphasized as they have also been associated with reduced stiffness [192, 193]. Regardless, dynamic and PNF stretching appear to be less detrimental to muscle function when compared to static stretching and may even enhance performance in some capacity despite stiffness reductions.

From a morphological perspective it is routinely reported that muscular cross-sectional area (CSA), muscle thickness and muscle volume are increased following resistance training [127, 132, 140]. Increases in these characteristics inevitably impact upon the force producing capabilities of the musculature [127, 128, 132]. CSA can be further defined as anatomical (ACSA) and physiological (PCSA) and since the PCSA represents the maximal number of actin-myosin crossbridges that can be activated in parallel during contraction, the maximal force-generating capacity of a given muscle is largely proportional to its total PCSA [127]. In addition, greater actin-myosin crossbridge formation consequently increases the stiffness of the musculature as a larger number of linkages occur during muscle activation, increasing the muscles' capacity to resist strain under highly stressful conditions. To support this, a number of researchers have noted that increases in muscle stiffness and strength reduce the amount of strain experienced by the muscle for a given force [127, 128, 130-132, 137, 140].

In combination with these muscle architectural alterations, increases in fascicle length following eccentrically focused training have been reported [129, 134, 137, 138, 140, 194]. These enhancements in fascicle length ranged from approximately $10 \%$ in the vastus lateralis to approximately $34 \%$ in the biceps femoris long head $[137,140]$. Fascicle length increases are commonly understood to occur by developing a greater number of sarcomeres in series, with Goldspink [195] providing the first review on this topic, however, more evidence is needed to support this. Considering that larger fascicle lengths appear to greatly influence muscle function by exhibiting superior force-velocity and force-length relationships, and superior shortening velocities in comparison to fascicles of shorter lengths [139, 141, 196-203], further exploration in the context of stiffness and Young's modulus is warranted. Further, it has been suggested that heightened fascicle lengths may even contribute to passive energy inputs [141]. From a muscular injury standpoint, longer fascicles are beneficial due to an enhanced capacity to tolerate absolute strain. This improved strain tolerance is understood to result from the greater number of sarcomeres in series allowing for strain to be distributed across more sarcomeres, thus reducing the strain experienced by individual sarcomeres [61]. This has considerable consequences for sarcomere functioning as less of the muscles working range would include the region of potential instability i.e. the descending limb of the length-tension curve of sarcomeres [61]. Highlighting the importance given to this, some authors even claiming that the addition of sarcomeres in series accounts for 85 to $100 \%$ of the repeated bout effect [204]. In addition, it has also been demonstrated that new sarcomores are added in-series near the musculotendinous junction [169, 205, 206], which has been proposed as the primary site of muscular injury [38, 39]. This may have important implications for the loading of the sarcomeres located near the musculotendinous junction.

In the applied research assessing muscle architecture and injury, a wealth of research has presented a range of positive injury-related outcomes associated with increased fascicle lengths that have resulted from various forms of eccentric training. Considering the widespread prevalence of hamstring injuries across the sporting arena, the vast majority of injury research in this area has focused on the hamstrings. To date, the use of eccentric hamstring strength training is the most widely researched and recommended evidence-based strategy for hamstring injury risk mitigation [207] and has significantly reduced the risk of primary and secondary injuries $(65 \%-85 \%)$ [208-210]. It has been proposed that eccentric strength training reduces hamstring injury risk through alterations to muscle architecture, specifically through the elongation of fascicles. Interestingly, when assessing fascicle lengths in response to 5-10 weeks of eccentric strength training, length increases of between $16 \%$ and $34 \%$ have been reported within the literature [137, 194, $211]$. In contrast, one study did not report any change in fascicle lengths with 6 weeks of Nordic hamstring training [212] which may have been due to the relatively short muscle lengths experienced during this exercise, potentially limiting adaptation [213]. Of note, in professional soccer players displaying relatively short Biceps Femoris long head (BFlh) fascicle lengths $(<10.6 \mathrm{~cm})$, there was a fourfold greater risk of HSI than in players with relatively longer fascicles [214]. In the same study it was reported that for every $5 \mathrm{~mm}$ increase in fascicle length, HSI risk was reduced by $75 \%$. In research assessing muscle architecture and athletic performance following injury, previously injured hamstrings expressed deficits of $30 \%$ in eccentric rate of force development on return to sport [215]. Interestingly, previous hamstring injury has also been associated with reduced fascicle lengths [216], however, owing to a lack of prospective studies, it is unclear whether these architectural changes are the cause or consequence of injury [216]. For a more detailed exploration of fascicle length and its relationship to performance and injury, Timmins et al. 
[141] have presented the most up to date review on this topic.

Although the majority of training studies have centred around types of contraction and plyometric training, deeper exploration into the influence of other training considerations such as ROM, training velocity and exposure to strain rates in relation to muscle architecture and stiffness outcomes is needed. Timmins et al. [141] maintains that an intricate relationship between the ROM that a muscle group routinely undertakes and the subsequent adaptations following an intervention may exist, a notion further supported by Guex et al. [213]. They suggest that exposing a muscle to greater elongations and ROM's larger than those typically experienced on a daily basis, while adding resistance, may increase muscle fascicle length independent of contraction mode. To support this Timmins [141] cited the different responses between young and elderly adults to eccentric resistance training, as elderly individuals appear to exhibit greater increases in fascicle length than their younger counterparts [138, 217]. It was suggested that elderly persons have, on average, a habitually reduced ROM. As such, by increasing the working range of their fascicles beyond what they are accustomed to in their normal daily living, longer fascicles result. The same authors also proposed that training with an emphasis on ROM may explain why some resistance interventions have elicited no fascicle length adaptations in younger adults who may already be accustomed to the ranges of motion utilised within the training studies [218]. To date, only one study has investigated the effect of training velocity on muscle architecture, comparing the effect of fast $(240 \%$ s) and slow $(90 \%)$ eccentric training [219]. However, the slow training group undertook their intervention through a reduced ROM $\left(35^{\circ}\right.$ less than the fast training group) which may have impacted upon the outcomes. Considering the absence of research investigating the effect of specific training velocities on muscle architectural adaptations, research in this area is of high priority.

\subsection{CONCLUSION}

Muscular injury continues to be a significant burden on athletes. Through developing proper understandings of the mechanical contributions to muscle and tendinous injury, appropriate intervention protocols can be established to reduce injury risk. The stiffness, strength, length, and elastic properties of the musculotendinous unit underpin the resilience of the structures in question. Further, the capacity of individual muscles and tendons to absorb elastic energy, protect against high forces, resist length changes and manage strain underpin the capabilities of the musculotendinous unit to resist injury under highly stressed conditions. It appears that although stress and strain are interrelated, muscle damage is largely dependent on the strain (stretch) experienced by the muscle as opposed to the stress (pressure/force), despite stress being present during muscle contraction. Protocols that develop the strength, stiffness regulation, and length characteristics of musculature best accustom athletic bodies to the stresses and strains experienced within their training protocols and competition events. To do this, athletes should seek strategies that provide them with the capacity to resist excessive strain, which is achieved through heightened strength and muscular stiffness. Correct muscle activation timing may also have a substantial role in injury occurrence and this should be examined in more detail in future research. Athletes should also seek to increase capacities to withstand larger amounts of absolute strain, which can be achieved through increasing the maximal elongation capabilities of the structures subject to length changes, such as fascicles.

\subsection{PRACTICAL APPLICATIONS}

- $\quad$ To reduce the risk of muscle injury, athletes should seek strategies that provide them with the capacity to resist strain. This is achieved through heightened strength, and superior stiffness regulation capabilities. Correct muscle activation timing may also have a substantial role in muscle injury risk mitigation.

- Athletes should also seek to increase their capacity to withstand larger amounts of absolute strain, which can be achieved through increasing the maximal elongation capabilities of the structures subject to length changes, such as fascicles.

- Plyometric and eccentric training appear to increase muscle strength and stiffness, CSA and fascicle lengths and should be undertaken to facilitate reduced injury risks.

- Static stretching negatively affects athletic performance and weakens tissue resilience due to reduced stiffness. In contrast, given their positive influence on neuromechanical function, dynamic and PNF stretching may be beneficial to athletic performance and should be prescribed ahead of static stretching. 


\section{REFERENCES}

1. Ekstrand J, Walden M, Hagglund $M$. Hamstring injuries have increased by $4 \%$ annually in men's professional football, since 2001: a 13-year longitudinal analysis of the UEFA Elite Club injury study. Br J Sports Med. 2016 Jun;50(12):731-7.

2. Elliott MC, Zarins B, Powell JW, Kenyon CD. Hamstring muscle strains in professional football players: a 10-year review. Am J Sports Med. 2011 Apr;39(4):843-50.

3. Gabbe BJ, Finch CF, Bennell KL, Wajswelner H. Risk factors for hamstring injuries in community level Australian football. Br J Sports Med. 2005 Feb;39(2):106-10.

4. Hoskins WT, Pollard H. INJURIES IN AUSTRALIAN RULES FOOTBALL: A Review of the Literature. Australas Chiropr Osteopathy. 2003 Jul;11(2):49-56.

5. Orchard J, Seward H. Epidemiology of injuries in the Australian Football League, seasons 1997-2000. Br J Sports Med. 2002 Feb;36(1):39-44.

6. Orchard JW, Seward H, Orchard JJ. Results of 2 decades of injury surveillance and public release of data in the Australian Football League. Am J Sports Med. 2013 Apr;41(4):734-41.

7. Colberg RE, Aune KT, Choi AJ, Fleisig GS. Incidence and Prevalence of Musculoskeletal Conditions in Collegiate Tennis Athletes. J Med Sci Tennis. 2015;20(3).

8. Moore IS, Ranson C, Mathema P. Injury Risk in International Rugby Union: Three-Year Injury Surveillance of the Welsh National Team. Orthop J Sports Med. 2015 Jul;3(7):2325967115596194.

9. Pollock N, Patel A, Chakraverty J, Suokas A, James SL, Chakraverty R. Time to return to full training is delayed and recurrence rate is higher in intratendinous ('c') acute hamstring injury in elite track and field athletes: clinical application of the British Athletics Muscle Injury Classification. Br J Sports Med. 2016 Mar;50(5):305-10.

10. Brooks JH, Fuller CW, Kemp SP, Reddin DB. Epidemiology of injuries in English professional rugby union: part 1 match injuries. Br J Sports Med. 2005 Oct;39(10):757-66.

11. Brooks JH, Fuller CW, Kemp SP, Reddin DB. Epidemiology of injuries in English professional rugby union: part 2 training Injuries. Br J Sports Med. 2005 Oct;39(10):767-75.

12. Brooks JH, Fuller CW, Kemp SP, Reddin DB. Incidence, risk, and prevention of hamstring muscle injuries in professional rugby union. Am J Sports Med. 2006 Aug;34(8):1297-306.

13. Brophy RH, Chehab EL, Barnes RP, Lyman S, Rodeo SA, Warren RF. Predictive value of orthopedic evaluation and injury history at the NFL combine. Med Sci Sports Exerc. 2008 Aug;40(8):136872 .

14. Feeley BT, Kennelly S, Barnes RP, Muller MS, Kelly BT, Rodeo SA, et al. Epidemiology of National Football League training camp injuries from 1998 to 2007. Am J Sports Med. 2008 Aug;36(8):1597603.

15. Chakravarthy J, Ramisetty N, Pimpalnerkar A, Mohtadi N. Surgical repair of complete proximal hamstring tendon ruptures in water skiers and bull riders: a report of four cases and review of the literature. Br J Sports Med. 2005 Aug;39(8):569-72.

16. Sallay PI, Friedman RL, Coogan PG, Garrett WE. Hamstring muscle injuries among water skiers. Functional outcome and prevention. Am J Sports Med. 1996 Mar-Apr;24(2):130-6.

17. Askling C, Lund H, Saartok T, Thorstensson A. Self-reported hamstring injuries in student-dancers. Scand J Med Sci Sports. 2002 Aug;12(4):230-5.

18. Kurosawa H, Nakasita K, Nakasita H, Sasaki $\mathrm{S}$, Takeda S. Complete avulsion of the hamstring tendons from the ischial tuberosity. A report of two cases sustained in judo. Br J Sports Med. 1996 Mar;30(1):72-4.

19. Garrett WE, Jr., Safran MR, Seaber AV, Glisson RR, Ribbeck BM. Biomechanical comparison of stimulated and nonstimulated skeletal muscle pulled to failure. Am J Sports Med. 1987 Sep-Oct;15(5):44854.

20. Lieber RL, Friden J. Muscle damage is not a function of muscle force but active muscle strain. J Appl Physiol (1985). 1993 Feb;74(2):520-6.

21. Lovering RM, Hakim M, Moorman CT, 3rd, De Deyne PG. The contribution of contractile preactivation to loss of function after a single lengthening contraction. J Biomech. 2005 Jul;38(7):1501-7.

22. Talbot JA, Morgan DL. The effects of stretch parameters on eccentric exercise-induced damage to toad skeletal muscle. J Muscle Res Cell Motil. 1998 Apr;19(3):237-45.

23. McHugh PT, T. Muscle strain injury vs muscle damage: Two mutually exclusive clinical entities. Transl Sports Med. 2019;0(0):1-7.

24. Nikolaou PK, Macdonald BL, Glisson RR, Seaber AV, Garrett WE, Jr. Biomechanical and histological evaluation of muscle after controlled strain injury. Am J Sports Med. 1987 Jan-Feb;15(1):9-14.

25. Friden J, Lieber RL. Structural and mechanical basis of exercise-induced muscle injury. Med Sci Sports Exerc. 1992 May;24(5):521-30.

26. Brockett CL, Morgan DL, Proske U. Human hamstring muscles adapt to eccentric exercise by changing optimum length. Med Sci Sports Exerc. 2001 May;33(5):783-90.

27. Timmins RG, Shield AJ, Williams MD, Opar DA. Is There Evidence to Support the Use of the Angle 
of Peak Torque as a Marker of Hamstring Injury and Re-Injury Risk? Sports Med. 2016 Jan;46(1):7-13.

28. Baker BA. An Old Problem: Aging and Skeletal-Muscle-Strain Injury. J Sport Rehabil. 2017 Apr;26(2):180-8.

29. Dueweke JJ, Awan TM, Mendias CL. Regeneration of Skeletal Muscle After Eccentric Injury. J Sport Rehabil. 2017 Apr;26(2):171-9.

30. Lieber RL, Woodburn TM, Friden J. Muscle damage induced by eccentric contractions of $25 \%$ strain. J Appl Physiol (1985). 1991 Jun;70(6):2498507.

31. Bizzini M, Mannion AF. Reliability of a new, hand-held device for assessing skeletal muscle stiffness. Clin Biomech (Bristol, Avon). 2003 Jun;18(5):459-61.

32. Zinder SM, Padua DA. Reliability, validity, and precision of a handheld myometer for assessing in vivo muscle stiffness. J Sport Rehabil. 2011 Aug $1 ; 20(3)$.

33. Butterfield TA, Herzog W. Effect of altering starting length and activation timing of muscle on fiber strain and muscle damage. J Appl Physiol (1985). 2006 May;100(5):1489-98.

34. Brooks SV, Faulkner JA. Severity of contraction-induced injury is affected by velocity only during stretches of large strain. J Appl Physiol (1985). 2001 Aug;91(2):661-6.

35. McCully KK, Faulkner JA. Characteristics of lengthening contractions associated with injury to skeletal muscle fibers. J Appl Physiol (1985). 1986 Jul;61(1):293-9.

36. Lynch GS, Faulkner JA. Contraction-induced injury to single muscle fibers: velocity of stretch does not influence the force deficit. Am J Physiol. 1998 Dec;275(6):C1548-54.

37. Warren GL, Hayes DA, Lowe DA, Armstrong RB. Mechanical factors in the initiation of eccentric contraction-induced injury in rat soleus muscle. J Physiol. 1993 May;464:457-75.

38. Garrett WE, Jr., Nikolaou PK, Ribbeck BM, Glisson RR, Seaber AV. The effect of muscle architecture on the biomechanical failure properties of skeletal muscle under passive extension. Am J Sports Med. 1988 Jan-Feb;16(1):7-12.

39. Best TM, McElhaney JH, Garrett WE, Jr., Myers BS. Axial strain measurements in skeletal muscle at various strain rates. J Biomech Eng. 1995 Aug;117(3):262-5.

40. Armstrong RB, Ogilvie RW, Schwane JA. Eccentric exercise-induced injury to rat skeletal muscle. J Appl Physiol Respir Environ Exerc Physiol. 1983 Jan;54(1):80-93.

41. Friden J, Seger J, Ekblom B. Sublethal muscle fibre injuries after high-tension anaerobic exercise. Eur J Appl Physiol Occup Physiol. 1988;57(3):360-8.
42. Friden J, Sjostrom M, Ekblom B. A morphological study of delayed muscle soreness. Experientia. 1981 May 15;37(5):506-7.

43. Friden J, Sjostrom M, Ekblom B. Myofibrillar damage following intense eccentric exercise in man. Int J Sports Med. 1983 Aug;4(3):170-6.

44. Newham DJ, McPhail G, Mills KR, Edwards RH. Ultrastructural changes after concentric and eccentric contractions of human muscle. J Neurol Sci. 1983 Sep;61(1):109-22.

45. Kuipers H, Drukker J, Frederik PM, Geurten P, van Kranenburg G. Muscle degeneration after exercise in rats. Int J Sports Med. 1983 Feb;4(1):45-51. 46. Lieber RL, Schmitz MC, Mishra DK, Friden J. Contractile and cellular remodeling in rabbit skeletal muscle after cyclic eccentric contractions. J Appl Physiol (1985). 1994 Oct;77(4):1926-34.

47. Friden J. Changes in human skeletal muscle induced by long-term eccentric exercise. Cell Tissue Res. 1984;236(2):365-72.

48. Ogilvie RW, Armstrong RB, Baird KE, Bottoms CL. Lesions in the rat soleus muscle following eccentrically biased exercise. Am J Anat. 1988 Aug;182(4):335-46.

49. Friden J, Kjorell U, Thornell LE. Delayed muscle soreness and cytoskeletal alterations: an immunocytological study in man. Int J Sports Med. 1984 Feb;5(1):15-8.

50. Armstrong RB. Initial events in exerciseinduced muscular injury. Med Sci Sports Exerc. 1990 Aug;22(4):429-35.

51. Duan C, Delp MD, Hayes DA, Delp PD, Armstrong RB. Rat skeletal muscle mitochondrial [Ca2+] and injury from downhill walking. J Appl Physiol (1985). 1990 Mar;68(3):1241-51.

52. Jenkins RR. Free radical chemistry. Relationship to exercise. Sports Med. 1988 Mar;5(3):156-70.

53. Jones DA, Newham DJ, Round JM, Tolfree SE. Experimental human muscle damage: morphological changes in relation to other indices of damage. J Physiol. 1986 Jun;375:435-48.

54. Lieber RL, Friden J. Selective damage of fast glycolytic muscle fibres with eccentric contraction of the rabbit tibialis anterior. Acta Physiol Scand. 1988 Aug;133(4):587-8.

55. Stauber WT. Eccentric action of muscles: physiology, injury, and adaptation. Exerc Sport Sci Rev. 1989;17:157-85.

56. Shah SB, Davis J, Weisleder N, Kostavassili I, McCulloch AD, Ralston E, et al. Structural and functional roles of desmin in mouse skeletal muscle during passive deformation. Biophys J. 2004 May;86(5):2993-3008.

57. Proske U, Morgan DL. Do cross-bridges contribute to the tension during stretch of passive 
muscle? J Muscle Res Cell Motil. 1999 Aug;20(56):433-42.

58. Wang K, McCarter R, Wright J, Beverly J, Ramirez-Mitchell R. Regulation of skeletal muscle stiffness and elasticity by titin isoforms: a test of the segmental extension model of resting tension. Proc Natl Acad Sci U S A. 1991 Aug 15;88(16):7101-5.

59. Gautel M. The sarcomeric cytoskeleton: who picks up the strain? Curr Opin Cell Biol. 2011 Feb;23(1):39-46.

60. Lieber RLJJos, science h. Biomechanical response of skeletal muscle to eccentric contractions. 2018;7(3):294-309.

61. Morgan DL. New insights into the behavior of muscle during active lengthening. Biophys J. 1990 Feb;57(2):209-21.

62. Horowits R, Kempner ES, Bisher ME, Podolsky RJ. A physiological role for titin and nebulin in skeletal muscle. Nature. 1986 Sep 1117;323(6084):160-4.

63. Wang K, McCarter R, Wright J, Beverly J, Ramirez-Mitchell R. Viscoelasticity of the sarcomere matrix of skeletal muscles. The titin-myosin composite filament is a dual-stage molecular spring. Biophys $\mathrm{J}$. 1993 Apr;64(4):1161-77.

64. Bressler BH, Clinch NF. The compliance of contracting skeletal muscle. J Physiol. 1974 Mar;237(3):477-93.

65. Bressler BH, Clinch NF. Cross bridges as the major source of compliance in contracting skeletal muscle. Nature. 1975 Jul 17;256(5514):221-2.

66. Cecchi G, Griffiths PJ, Taylor S. Muscular contraction: kinetics of crossbridge attachment studied by high-frequency stiffness measurements. Science. 1982 Jul 2;217(4554):70-2.

67. Ford LE, Huxley AF, Simmons RM. Tension transients during the rise of tetanic tension in frog muscle fibres. J Physiol. 1986 Mar;372:595-609.

68. Gordon AM, Huxley AF, Julian FJ. The variation in isometric tension with sarcomere length in vertebrate muscle fibres. J Physiol. 1966 May;184(1):170-92.

69. Huxley AF. Muscle structure and theories of contraction. Prog Biophys Biophys Chem. 1957;7:255318.

70. Herzog W. The multiple roles of titin in muscle contraction and force production. Biophys Rev. 2018 Aug;10(4):1187-99.

71. Herzog W. The role of titin in eccentric muscle contraction. J Exp Biol. 2014 Aug 15;217(Pt 16):2825-33.

72. Nishikawa KC, Monroy JA, Uyeno TE, Yeo SH, Pai DK, Lindstedt SL. Is titin a 'winding filament'? A new twist on muscle contraction. Proc Biol Sci. 2012 Mar 7;279(1730):981-90.

73. Labeit D, Watanabe K, Witt C, Fujita H, Wu Y, Lahmers S, et al. Calcium-dependent molecular spring elements in the giant protein titin. Proc Natl Acad Sci U S A. 2003 Nov 11;100(23):13716-21.

74. DuVall MM, Gifford JL, Amrein M, Herzog W. Altered mechanical properties of titin immunoglobulin domain 27 in the presence of calcium. Eur Biophys J. 2013 Apr;42(4):301-7.

75. Granata KP, Padua DA, Wilson SE. Gender differences in active musculoskeletal stiffness. Part II. Quantification of leg stiffness during functional hopping tasks. J Electromyogr Kinesiol. 2002 Apr;12(2):127-35.

76. Williams DS, 3rd, Davis IM, Scholz JP, Hamill J, Buchanan TS. High-arched runners exhibit increased leg stiffness compared to low-arched runners. Gait Posture. 2004 Jun;19(3):263-9.

77. Williams DS, McClay Davis I, Scholz JP, Hamill J, Buchanan TS. Lower extremity stiffness in runners with different foot types. Gait and posture. 2003.

78. Williams DS, 3rd, McClay IS, Hamill J. Arch structure and injury patterns in runners. Clin Biomech (Bristol, Avon). 2001 May;16(4):341-7.

79. Sharma P, Maffulli N. Biology of tendon injury: healing, modeling and remodeling. J Musculoskelet Neuronal Interact. 2006 AprJun;6(2):181-90.

80. Lohmander LS, Englund PM, Dahl LL, Roos EM. The long-term consequence of anterior cruciate ligament and meniscus injuries: osteoarthritis. Am J Sports Med. 2007 Oct;35(10):1756-69.

81. Arampatzis A, Schade F, Walsh M, Bruggemann GP. Influence of leg stiffness and its effect on myodynamic jumping performance. $\mathrm{J}$ Electromyogr Kinesiol. 2001 Oct;11(5):355-64.

82. Dietz V, Schmidtbleicher D, Noth J. Neuronal mechanisms of human locomotion. J Neurophysiol. 1979 Sep;42(5):1212-22.

83. Gollhofer A, Schmidtbleicher D, Dietz V. Regulation of muscle stiffness in human locomotion. Int J Sports Med. 1984 Feb;5(1):19-22.

84. Hoffer JA, Andreassen S. Regulation of soleus muscle stiffness in premammillary cats: intrinsic and reflex components. J Neurophysiol. 1981 Feb;45(2):267-85.

85. Kuitunen S, Komi PV, Kyrolainen H. Knee and ankle joint stiffness in sprint running. Med Sci Sports Exerc. 2002 Jan;34(1):166-73.

86. Huxley AF, Peachey LD. The maximum length for contraction in vertebrate straiated muscle. J Physiol. 1961 Apr;156:150-65.

87. Lieber RL, Baskin RJ. Intersarcomere dynamics of single muscle fibers during fixed-end tetani. J Gen Physiol. 1983 Sep;82(3):347-64.

88. Collette J, Jinha A, Herzog W. Mechanics of Sarcomeres in Series and Instability-JURA Best Paper Award 2016-2017. Journal of Undergraduate Research in Alberta. 2017;6:8-17. 
89. Johnston K, Jinha A, Herzog W. The role of sarcomere length non-uniformities in residual force enhancement of skeletal muscle myofibrils. R Soc Open Sci. 2016 Mar;3(3):150657.

90. Burton K, Zagotta WN, Baskin RJ. Sarcomere length behaviour along single frog muscle fibres at different lengths during isometric tetani. J Muscle Res Cell Motil. 1989 Feb;10(1):67-84.

91. Morgan DL, Mochon S, Julian FJ. A quantitative model of intersarcomere dynamics during fixed-end contractions of single frog muscle fibers. Biophys J. 1982 Aug;39(2):189-96.

92. Uchiyama Y, Tamaki T, Fukuda H. Relationship between functional deficit and severity of experimental fast-strain injury of rat skeletal muscle. Eur J Appl Physiol. 2001 Jul;85(1-2):1-9.

93. Orchard JW. Hamstrings are most susceptible to injury during the early stance phase of sprinting. $\mathrm{Br}$ J Sports Med. 2012 Feb;46(2):88-9.

94. Macpherson PC, Dennis RG, Faulkner JA. Sarcomere dynamics and contraction-induced injury to maximally activated single muscle fibres from soleus muscles of rats. J Physiol. 1997 Apr 15;500 ( Pt 2):52333.

95. Garrett WE, Jr. Muscle strain injuries. Am J Sports Med. 1996;24(6 Suppl):S2-8.

96. Marqueste T, Giannesini B, Fur YL, Cozzone PJ, Bendahan D. Comparative MRI analysis of T2 changes associated with single and repeated bouts of downhill running leading to eccentric-induced muscle damage. J Appl Physiol (1985). 2008 Jul;105(1):299307.

97. Frimel TN, Walter GA, Gibbs JD, Gaidosh GS, Vandenborne K. Noninvasive monitoring of muscle damage during reloading following limb disuse. Muscle Nerve. 2005 Nov;32(5):605-12.

98. Foley JM, Jayaraman RC, Prior BM, Pivarnik JM, Meyer RA. MR measurements of muscle damage and adaptation after eccentric exercise. J Appl Physiol (1985). 1999 Dec;87(6):2311-8.

99. Baker BA, Mercer RR, Geronilla KB, Kashon ML, Miller GR, Cutlip RG. Impact of repetition number on muscle performance and histological response. Med Sci Sports Exerc. 2007 Aug;39(8):1275-81.

100. Lovering RM, McMillan AB, Gullapalli RP. Location of myofiber damage in skeletal muscle after lengthening contractions. Muscle Nerve. 2009 Oct;40(4):589-94.

101. Gordon AM, Huxley AF, Julian FJ. Tension development in highly stretched vertebrate muscle fibres. J Physiol. 1966 May;184(1):143-69.

102. Lieber RL, Friden J. Mechanisms of muscle injury gleaned from animal models. Am J Phys Med Rehabil. 2002 Nov;81(11 Suppl):S70-9.

103. Yeung SS, Suen AM, Yeung EW. A prospective cohort study of hamstring injuries in competitive sprinters: preseason muscle imbalance as a possible risk factor. $\mathrm{Br}$ J Sports Med. 2009 Aug;43(8):589-94.

104. Duhig S, Shield AJ, Opar D, Gabbett TJ, Ferguson C, Williams M. Effect of high-speed running on hamstring strain injury risk. Br J Sports Med. 2016 Dec;50(24):1536-40.

105. Arnason A, Andersen TE, Holme I, Engebretsen L, Bahr R. Prevention of hamstring strains in elite soccer: an intervention study. Scand J Med Sci Sports. 2008 Feb;18(1):40-8.

106. Dadebo B, White J, George KP. A survey of flexibility training protocols and hamstring strains in professional football clubs in England. $\mathrm{Br} \mathrm{J}$ Sports Med. 2004 Aug;38(4):388-94.

107. Ekstrand J, Gillquist J. The frequency of muscle tightness and injuries in soccer players. Am J Sports Med. 1982 Mar-Apr;10(2):75-8.

108. Woods C, Hawkins R, Hulse M, Hodson A. The Football Association Medical Research Programme: an audit of injuries in professional football-analysis of preseason injuries. $\mathrm{Br} \mathrm{J}$ Sports Med. 2002 Dec;36(6):436-41; discussion 41.

109. Woods C, Hawkins RD, Maltby S, Hulse M, Thomas A, Hodson A, et al. The Football Association Medical Research Programme: an audit of injuries in professional football--analysis of hamstring injuries. Br J Sports Med. 2004 Feb;38(1):36-41.

110. Gabbett TJ, Ullah S. Relationship between running loads and soft-tissue injury in elite team sport athletes. J Strength Cond Res. 2012 Apr;26(4):953-60. 111. Malone S, Roe M, Doran DA, Gabbett TJ, Collins K. High chronic training loads and exposure to bouts of maximal velocity running reduce injury risk in elite Gaelic football. J Sci Med Sport. 2017 Mar;20(3):250-4.

112. Kraemer WJ, Ratamess NA, French DN. Resistance training for health and performance. Curr Sports Med Rep. 2002 Jun;1(3):165-71.

113. Straub WF. Effect of overload training procedures upon velocity and accuracy of the overarm throw. Res Q. 1968 May;39(2):370-9.

114. Ramirez-Campillo R, Henriquez-Olguin C, Burgos C, Andrade DC, Zapata D, Martinez C, et al. Effect of Progressive Volume-Based Overload During Plyometric Training on Explosive and Endurance Performance in Young Soccer Players. J Strength Cond Res. 2015 Jul;29(7):1884-93.

115. McNicol AJ, O'Brien BJ, Paton CD, Knez WL. The effects of increased absolute training intensity on adaptations to endurance exercise training. J Sci Med Sport. 2009 Jul;12(4):485-9.

116. Delecluse C. Influence of strength training on sprint running performance. Current findings and implications for training. Sports Med. 1997 Sep;24(3):147-56. 
117. Baar K, Blough E, Dineen B, Esser K. Transcriptional regulation in response to exercise. Exerc Sport Sci Rev. 1999;27:333-79.

118. Carson JA. The regulation of gene expression in hypertrophying skeletal muscle. Exerc Sport Sci Rev. 1997;25:301-20.

119. Kongsgaard M, Aagaard P, Kjaer M, Magnusson SP. Structural Achilles tendon properties in athletes subjected to different exercise modes and in Achilles tendon rupture patients. J Appl Physiol (1985). 2005 Nov;99(5):1965-71.

120. Kongsgaard M, Reitelseder S, Pedersen TG, Holm L, Aagaard P, Kjaer M, et al. Region specific patellar tendon hypertrophy in humans following resistance training. Acta Physiol (Oxf). 2007 Oct;191(2):111-21.

121. Kubo K, Morimoto M, Komuro T, Yata $\mathrm{H}$, Tsunoda N, Kanehisa H, et al. Effects of plyometric and weight training on muscle-tendon complex and jump performance. Med Sci Sports Exerc. 2007 Oct;39(10):1801-10.

122. Selye H. Stress and the general adaptation syndrome. Br Med J. 1950 Jun 17;1(4667):1383-92.

123. Shadwick RE. Elastic energy storage in tendons: mechanical differences related to function and age. J Appl Physiol (1985). 1990 Mar;68(3):1033-40.

124. Waugh CM, Korff T, Fath F, Blazevich AJ. Rapid force production in children and adults: mechanical and neural contributions. Med Sci Sports Exerc. 2013 Apr;45(4):762-71.

125. Kubo K, Kanehisa H, Kawakami Y, Fukanaga T. Growth changes in the elastic properties of human tendon structures. Int J Sports Med. 2001 Feb;22(2):138-43.

126. Nakagawa Y, Hayashi K, Yamamoto N, Nagashima K. Age-related changes in biomechanical properties of the Achilles tendon in rabbits. Eur J Appl Physiol Occup Physiol. 1996;73(1-2):7-10.

127. Aagaard P, Andersen JL, Dyhre-Poulsen P, Leffers AM, Wagner A, Magnusson SP, et al. A mechanism for increased contractile strength of human pennate muscle in response to strength training: changes in muscle architecture. J Physiol. 2001 Jul 15;534(Pt. 2):613-23.

128. Alegre LM, Jimenez F, Gonzalo-Orden JM, Martin-Acero R, Aguado X. Effects of dynamic resistance training on fascicle length and isometric strength. J Sports Sci. 2006 May;24(5):501-8.

129. Baroni BM, Geremia JM, Rodrigues R, De Azevedo Franke R, Karamanidis K, Vaz MA. Muscle architecture adaptations to knee extensor eccentric training: rectus femoris vs. vastus lateralis. Muscle Nerve. 2013 Oct;48(4):498-506.

130. Blazevich AJ, Cannavan D, Coleman DR, Horne S. Influence of concentric and eccentric resistance training on architectural adaptation in human quadriceps muscles. J Appl Physiol (1985). 2007 Nov;103(5):1565-75.

131. Campbell EL, Seynnes OR, Bottinelli R, McPhee JS, Atherton PJ, Jones DA, et al. Skeletal muscle adaptations to physical inactivity and subsequent retraining in young men. Biogerontology. 2013 Jun;14(3):247-59.

132. Duclay J, Martin A, Duclay A, Cometti G, Pousson M. Behavior of fascicles and the myotendinous junction of human medial gastrocnemius following eccentric strength training. Muscle Nerve. 2009 Jun;39(6):819-27.

133. Foure A, Nordez A, Cornu C. Plyometric training effects on Achilles tendon stiffness and dissipative properties. J Appl Physiol (1985). 2010 Sep;109(3):849-54.

134. Franchi MV, Atherton PJ, Reeves ND, Fluck M, Williams J, Mitchell WK, et al. Architectural, functional and molecular responses to concentric and eccentric loading in human skeletal muscle. Acta Physiol (Oxf). 2014 Mar;210(3):642-54.

135. Kubo K, Kanehisa H, Fukunaga T. Effects of resistance and stretching training programmes on the viscoelastic properties of human tendon structures in vivo. J Physiol. 2002 Jan 1;538(Pt 1):219-26.

136. Kubo K, Kanehisa H, Ito M, Fukunaga $\mathrm{T}$. Effects of isometric training on the elasticity of human tendon structures in vivo. J Appl Physiol (1985). 2001 Jul;91(1):26-32.

137. Potier TG, Alexander CM, Seynnes OR. Effects of eccentric strength training on biceps femoris muscle architecture and knee joint range of movement. Eur J Appl Physiol. 2009 Apr;105(6):939-44.

138. Reeves ND, Maganaris CN, Longo S, Narici MV. Differential adaptations to eccentric versus conventional resistance training in older humans. Exp Physiol. 2009 Jul;94(7):825-33.

139. Reeves ND, Narici MV, Maganaris CN. In vivo human muscle structure and function: adaptations to resistance training in old age. Exp Physiol. 2004 Nov;89(6):675-89.

140. Seynnes OR, de Boer M, Narici MV. Early skeletal muscle hypertrophy and architectural changes in response to high-intensity resistance training. J Appl Physiol (1985). 2007 Jan;102(1):368-73.

141. Timmins RG, Shield AJ, Williams MD, Lorenzen C, Opar DA. Architectural adaptations of muscle to training and injury: a narrative review outlining the contributions by fascicle length, pennation angle and muscle thickness. $\mathrm{Br} \mathrm{J}$ Sports Med. 2016 Dec;50(23):1467-72.

142. Thelen DG, Chumanov ES, Hoerth DM, Best TM, Swanson SC, Li L, et al. Hamstring muscle kinematics during treadmill sprinting. Med Sci Sports Exerc. 2005 Jan;37(1):108-14.

143. Thelen DG, Chumanov ES, Best TM, Swanson SC, Heiderscheit BC. Simulation of biceps 
femoris musculotendon mechanics during the swing phase of sprinting. Med Sci Sports Exerc. 2005 Nov;37(11):1931-8.

144. Yu B, Queen RM, Abbey AN, Liu Y, Moorman CT, Garrett WE. Hamstring muscle kinematics and activation during overground sprinting. J Biomech. 2008 Nov 14;41(15):3121-6.

145. Bojsen-Møller J, Magnusson SP, Rasmussen LR, Kjaer M, Aagaard P. Muscle performance during maximal isometric and dynamic contractions is influenced by the stiffness of the tendinous structures. . J Appl Physiol. 2005;99(3):986-94.

146. Bret C, Rahmani A, Dufour AB, Messonnier L, Lacour JR. Leg strength and stiffness as ability factors in $100 \mathrm{~m}$ sprint running. J Sports Med Phys Fitness. 2002;42(3):274-81.

147. Kalkhoven JT, Watsford ML. The relationship between mechanical stiffness and athletic performance markers in sub-elite footballers. J Sports Sci. 2018 May;36(9):1022-9.

148. Burgess KE, Connick MJ, Graham-Smith P, Pearson SJ. Plyometric vs. isometric training influences on tendon properties and muscle output. J Strength Cond Res. 2007 Aug;21(3):986-9.

149. Dal Pupo J, Dias JA, Gheller RG, Detanico D, dos Santos SG. Stiffness, intralimb coordination, and joint modulation during a continuous vertical jump test. Sports Biomech. 2013 Sep;12(3):259-71.

150. Fouré A, Nordez A, McNair P, Cornu C. Effects of plyometric training on both active and passive parts of the plantarflexors series elastic component stiffness of muscle-tendon complex. Eur J Appl Physiol. 2011;111(3):539-48.

151. Kubo K, Yata H, Kanehisa H, Fukunaga T. Effects of isometric squat training on the tendon stiffness and jump performance. Eur J Appl Physiol. 2006 Feb;96(3):305-14.

152. Woods MA, Watsford ML, Cavanagh BP, Pruyn EC. Factors affecting jump performance in professional Australian rules footballers. J Sports Med Phys Fitness. 2015 Oct;55(10):1114-21.

153. Wu YK, Lien YH, Lin KH, Shih TT, Wang TG, Wang HK. Relationships between three potentiation effects of plyometric training and performance. Scand J Med Sci Sports. 2010 Feb;20(1):e80-6.

154. Raiteri BJ, Cresswell AG, Lichtwark GA. Muscle-tendon length and force affect human tibialis anterior central aponeurosis stiffness in vivo. Proc Natl Acad Sci U S A. 2018 Apr 3;115(14):E3097-E105.

155. Secomb JL, Lundgren LE, Farley OR, Tran TT, Nimphius S, Sheppard JM. Relationships Between Lower-Body Muscle Structure and Lower-Body Strength, Power, and Muscle-Tendon Complex Stiffness. J Strength Cond Res. 2015 Aug;29(8):22218 .
156. Wilson GJ, Murphy AJ, Pryor JF. Musculotendinous stiffness: its relationship to eccentric, isometric, and concentric performance. J Appl Physiol (1985). 1994 Jun;76(6):2714-9.

157. Brughelli M, Cronin J. A review of research on the mechanical stiffness in running and jumping: methodology and implications. Scand J Med Sci Sports. 2008 Aug;18(4):417-26.

158. Butler RJ, Crowell HP, 3rd, Davis IM. Lower extremity stiffness: implications for performance and injury. Clin Biomech (Bristol, Avon). 2003 Jul;18(6):511-7.

159. Pousson M, Van Hoecke J, Goubel F. Changes in elastic characteristics of human muscle induced by eccentric exercise. $\mathrm{J}$ Biomech. 1990;23(4):343-8.

160. Higbie EJ, Cureton KJ, Warren GL, 3rd, Prior BM. Effects of concentric and eccentric training on muscle strength, cross-sectional area, and neural activation. J Appl Physiol (1985). 1996 Nov;81(5):2173-81.

161. Jones DA, Rutherford OM. Human muscle strength training: the effects of three different regimens and the nature of the resultant changes. J Physiol. 1987 Oct;391:1-11.

162. Spurrs RW, Murphy AJ, Watsford ML. The effect of plyometric training on distance running performance. Eur J Appl Physiol. 2003 Mar;89(1):1-7.

163. Rosenbaum D, Hennig EM. The influence of stretching and warm-up exercises on Achilles tendon reflex activity. J Sports Sci. 1995 Dec;13(6):481-90.

164. Wilson GJ, Elliott BC, Wood GA. Stretch shorten cycle performance enhancement through flexibility training. Med Sci Sports Exerc. 1992 Jan;24(1):116-23.

165. Behm DG, Blazevich AJ, Kay AD, McHugh M. Acute effects of muscle stretching on physical performance, range of motion, and injury incidence in healthy active individuals: a systematic review. Appl Physiol Nutr Metab. 2016 Jan;41(1):1-11.

166. Behm DG, Chaouachi A. A review of the acute effects of static and dynamic stretching on performance. Eur J Appl Physiol. 2011 Nov;111(11):2633-51.

167. Wilson GJ, Wood GA, Elliott BC. The relationship between stiffness of the musculature and static flexibility: an alternative explanation for the occurrence of muscular injury. Int J Sports Med. 1991 Aug;12(4):403-7.

168. Magnusson SP, Simonsen EB, Aagaard P, Sorensen H, Kjaer M. A mechanism for altered flexibility in human skeletal muscle. J Physiol. 1996 Nov 15;497 ( Pt 1):291-8.

169. Williams PE, Goldspink G. Longitudinal growth of striated muscle fibres. J Cell Sci. 1971 Nov;9(3):751-67. 
170. Gleim GW, McHugh MP. Flexibility and its effects on sports injury and performance. Sports Med. 1997 Nov;24(5):289-99.

171. Herbert RD, Gabriel M. Effects of stretching before and after exercising on muscle soreness and risk of injury: systematic review. BMJ. 2002 Aug 31;325(7362):468.

172. Small K, Mc Naughton L, Matthews M. A systematic review into the efficacy of static stretching as part of a warm-up for the prevention of exerciserelated injury. Res Sports Med. 2008;16(3):213-31.

173. Cowan D, Jones B, Tomlinson P, Robinson J, Polly D. The epidemiology of physical training injuries in US infantry trainees: methodology, population, and risk factors. US Army Research Institute of Environmental Medicine Technology. 1988;NO:T489.

174. CL B, JJ K, BH J, JM H, Vaughan, editors. An approach to musculoskeletal profiling of women in sports. In: Cantu IR, Gillesoie W (eds) Sports medicine, sports science: bridging the gap. Lexington, MA: Health Publications; 1982.

175. Behm DG, Button DC, Butt JC. Factors affecting force loss with prolonged stretching. Can J Appl Physiol. 2001 Jun;26(3):261-72.

176. Behm DG, Bambury A, Cahill F, Power K. Effect of acute static stretching on force, balance, reaction time, and movement time. Med Sci Sports Exerc. 2004 Aug;36(8):1397-402.

177. Behm DG, Bradbury EE, Haynes AT, Hodder JN, Leonard AM, Paddock NR. Flexibility is not Related to Stretch-Induced Deficits in Force or Power. J Sports Sci Med. 2006;5(1):33-42.

178. Behm DG, Kibele A. Effects of differing intensities of static stretching on jump performance. Eur J Appl Physiol. 2007 Nov;101(5):587-94.

179. Fowles JR, Sale DG, MacDougall JD. Reduced strength after passive stretch of the human plantarflexors. J Appl Physiol (1985). 2000 Sep;89(3):1179-88.

180. Kokkonen J, Nelson AG, Cornwell A. Acute muscle stretching inhibits maximal strength performance. Res Q Exerc Sport. 1998 Dec;69(4):4115.

181. Nelson AG, Allen JD, Cornwell A, Kokkonen J. Inhibition of maximal voluntary isometric torque production by acute stretching is joint-angle specific. Res Q Exerc Sport. 2001 Mar;72(1):68-70.

182. Power K, Behm D, Cahill F, Carroll M, Young W. An acute bout of static stretching: effects on force and jumping performance. Med Sci Sports Exerc. 2004 Aug;36(8):1389-96.

183. Bacurau RF, Monteiro GA, Ugrinowitsch C, Tricoli V, Cabral LF, Aoki MS. Acute effect of a ballistic and a static stretching exercise bout on flexibility and maximal strength. J Strength Cond Res. 2009 Jan;23(1):304-8.
184. Beedle B, Rytter SJ, Healy RC, Ward TR. Pretesting static and dynamic stretching does not affect maximal strength. J Strength Cond Res. 2008 Nov;22(6):1838-43.

185. Christensen BK, Nordstrom BJ. The effects of proprioceptive neuromuscular facilitation and dynamic stretching techniques on vertical jump performance. J Strength Cond Res. 2008 Nov;22(6):1826-31.

186. Gelen E. Acute effects of different warm-up methods on sprint, slalom dribbling, and penalty kick performance in soccer players. J Strength Cond Res. 2010 Apr;24(4):950-6.

187. Jaggers JR, Swank AM, Frost KL, Lee CD. The acute effects of dynamic and ballistic stretching on vertical jump height, force, and power. J Strength Cond Res. 2008 Nov;22(6):1844-9.

188. Samuel MN, Holcomb WR, Guadagnoli MA, Rubley MD, Wallmann H. Acute effects of static and ballistic stretching on measures of strength and power. J Strength Cond Res. 2008 Sep;22(5):1422-8.

189. Sekir U, Arabaci R, Akova B, Kadagan SM. Acute effects of static and dynamic stretching on leg flexor and extensor isokinetic strength in elite women athletes. Scand J Med Sci Sports. 2010 Apr;20(2):26881.

190. Torres EM, Kraemer WJ, Vingren JL, Volek JS, Hatfield DL, Spiering BA, et al. Effects of stretching on upper-body muscular performance. J Strength Cond Res. 2008 Jul;22(4):1279-85.

191. Unick J, Kieffer HS, Cheesman W, Feeney A. The acute effects of static and ballistic stretching on vertical jump performance in trained women. J Strength Cond Res. 2005 Feb;19(1):206-12.

192. Kay AD, Husbands-Beasley J, Blazevich AJ. Effects of Contract-Relax, Static Stretching, and Isometric Contractions on Muscle-Tendon Mechanics. Med Sci Sports Exerc. 2015 Oct;47(10):2181-90.

193. Herda TJ, Herda ND, Costa PB, Walter-Herda AA, Valdez AM, Cramer JT. The effects of dynamic stretching on the passive properties of the muscletendon unit. J Sports Sci. 2013;31(5):479-87.

194. Bourne MN, Duhig SJ, Timmins RG, Williams MD, Opar DA, Al Najjar A, et al. Impact of the Nordic hamstring and hip extension exercises on hamstring architecture and morphology: implications for injury prevention. $\mathrm{Br}$ J Sports Med. 2017 Mar;51(5):469-77.

195. Goldspink G. Malleability of the motor system: a comparative approach. J Exp Biol. 1985 Mar;115:375-91.

196. Blazevich AJ. Effects of physical training and detraining, immobilisation, growth and aging on human fascicle geometry. Sports Med. 2006;36(12):1003-17.

197. Bodine SC, Roy RR, Meadows DA, Zernicke RF, Sacks RD, Fournier M, et al. Architectural, histochemical, and contractile characteristics of a 
unique biarticular muscle: the cat semitendinosus. J Neurophysiol. 1982 Jul;48(1):192-201.

198. Butterfield TA, Leonard TR, Herzog W. Differential serial sarcomere number adaptations in knee extensor muscles of rats is contraction type dependent. J Appl Physiol (1985). 2005 Oct;99(4):1352-8.

199. Jones C, Allen T, Talbot J, Morgan DL, Proske U. Changes in the mechanical properties of human and amphibian muscle after eccentric exercise. Eur J Appl Physiol Occup Physiol. 1997;76(1):21-31.

200. Lieber RL, Friden J. Functional and clinical significance of skeletal muscle architecture. Muscle Nerve. 2000 Nov;23(11):1647-66.

201. Lieber RL, Ward SR. Skeletal muscle design to meet functional demands. Philos Trans R Soc Lond B Biol Sci. 2011 May 27;366(1570):1466-76.

202. Lynn R, Morgan DL. Decline running produces more sarcomeres in rat vastus intermedius muscle fibers than does incline running. J Appl Physiol (1985). 1994 Sep;77(3):1439-44.

203. Lynn R, Talbot JA, Morgan DL. Differences in rat skeletal muscles after incline and decline running. J Appl Physiol (1985). 1998 Jul;85(1):98-104.

204. Morgan DL, Talbot JA. The addition of sarcomeres in series is the main protective mechanism following eccentric exercise. Journal of Mechanics in Medicine and Biology. 2002;2(03n04):421-31.

205. Williams PE, Goldspink G. The effect of immobilization on the longitudinal growth of striated muscle fibres. J Anat. 1973 Oct;116(Pt 1):45-55.

206. Williams PE, Goldspink G. Changes in sarcomere length and physiological properties in immobilized muscle. J Anat. 1978 Dec;127(Pt 3):45968.

207. Buckthorpe M, Wright S, Bruce-Low S, Nanni G, Sturdy T, Gross AS, et al. Recommendations for hamstring injury prevention in elite football: translating research into practice. Br J Sports Med. 2018 Nov 9.

208. Goode AP, Reiman MP, Harris L, DeLisa L, Kauffman A, Beltramo D, et al. Eccentric training for prevention of hamstring injuries may depend on intervention compliance: a systematic review and meta-analysis. Br J Sports Med. 2015 Mar;49(6):34956.

209. Petersen J, Thorborg K, Nielsen MB, BudtzJorgensen E, Holmich P. Preventive effect of eccentric training on acute hamstring injuries in men's soccer: a cluster-randomized controlled trial. Am J Sports Med. 2011 Nov;39(11):2296-303.

210. Tyler TF, Schmitt BM, Nicholas SJ, McHugh MP. Rehabilitation After Hamstring-Strain Injury Emphasizing Eccentric Strengthening at Long Muscle Lengths: Results of Long-Term Follow-Up. J Sport Rehabil. 2017 Apr;26(2):131-40.

211. Pollard CW, Opar DA, Williams MD, Bourne MN, Timmins RG. Razor hamstring curl and Nordic hamstring exercise architectural adaptations: Impact of exercise selection and intensity. Scand J Med Sci Sports. 2019 Jan 10.

212. Seymore KD, Domire ZJ, DeVita P, Rider PM, Kulas AS. The effect of Nordic hamstring strength training on muscle architecture, stiffness, and strength. Eur J Appl Physiol. 2017 May;117(5):943-53.

213. Guex K, Degache F, Morisod C, Sailly M, Millet GP. Hamstring Architectural and Functional Adaptations Following Long vs. Short Muscle Length Eccentric Training. Front Physiol. 2016;7:340.

214. Timmins RG, Bourne MN, Shield AJ, Williams MD, Lorenzen C, Opar DA. Short biceps femoris fascicles and eccentric knee flexor weakness increase the risk of hamstring injury in elite football (soccer): a prospective cohort study. Br J Sports Med. 2016 Dec;50(24):1524-35.

215. Opar DA, Williams MD, Timmins RG, Dear NM, Shield AJ. Rate of torque and electromyographic development during anticipated eccentric contraction is lower in previously strained hamstrings. Am J Sports Med. 2013 Jan;41(1):116-25.

216. Timmins RG, Shield AJ, Williams MD, Lorenzen C, Opar DA. Biceps femoris long head architecture: a reliability and retrospective injury study. Med Sci Sports Exerc. 2015 May;47(5):905-13. 217. Reeves ND, Narici MV, Maganaris CN. Effect of resistance training on skeletal muscle-specific force in elderly humans. J Appl Physiol (1985). 2004 Mar;96(3):885-92.

218. Blazevich AJ, Gill ND, Bronks R, Newton RU. Training-specific muscle architecture adaptation after 5-wk training in athletes. Med Sci Sports Exerc. 2003 Dec;35(12):2013-22.

219. Sharifnezhad A, Marzilger R, Arampatzis A. Effects of load magnitude, muscle length and velocity during eccentric chronic loading on the longitudinal growth of the vastus lateralis muscle. J Exp Biol. 2014 Aug 1;217(Pt 15):2726-33. 